\title{
Interfacial Polymerization within a Simplified Microfluidic Device: Capturing Capsules
}

\author{
Elizabeth Quevedo, Jeremy Steinbacher, and D. Tyler McQuade* \\ Cornell University, Department of Chemistry and Chemical Biology, Baker Laboratory, Ithaca NY \\ 14853-1301
}

Supplementary Information

Mesofluidic Device.
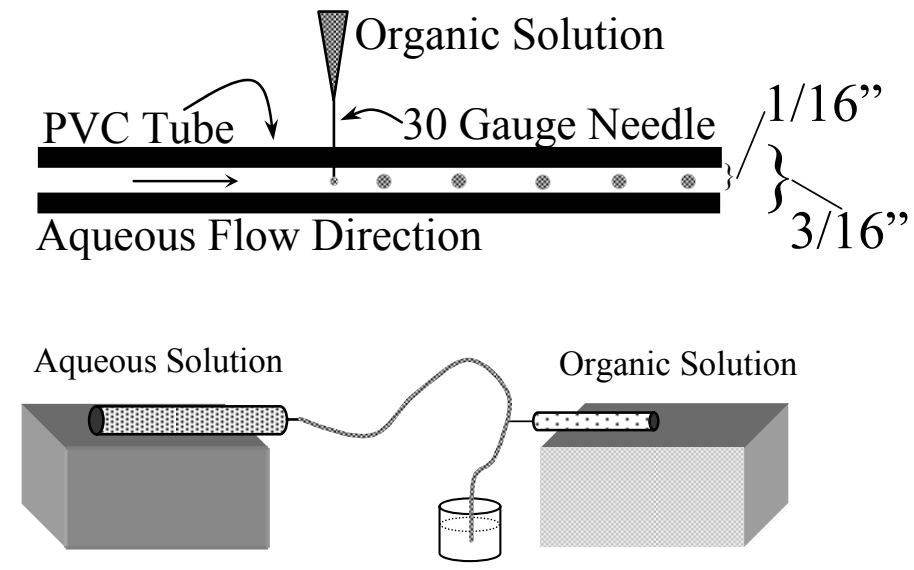

Solution Preparation. In all experiments in this paper, the continuous phase was a glycerol (Mallinckrodt AR) water solution $(30 \% \mathrm{w} / \mathrm{v})$ used to standardize the viscosity. In experiments involving interfacial polymerization, polyethyleneimine (PEI, 50\% in water) was added as the aqueous monomer to generate a $2.0 \%(\mathrm{v} / \mathrm{v})$ mixture.

In the phase behavior study, a $(2 \% \mathrm{v} / \mathrm{v})$ Tween 80 (Aldrich) in a $3: 1$ cyclohexane/chloroform solution was used as the organic phase. In experiments involving interfacial polymerization, a solution of sebacoyl chloride (SC, Acros, 92\%) and trimesoyl chloride (TMC, 1, 3, 5- benzene tricarbonyl trichloride, Acros, 98\%) as the monomers (1.34 M and $0.266 \mathrm{M}$, respectively) in 3:1 cyclohexane/chloroform was used to prepare oil-cored capsules. Chloroform (J. T. Baker) and cyclohexane (Mallinckrodt Chemicals) were purchased and used from a commercially available source.

Equipment and Procedures. The continuous aqueous phase flows in polyvinylchloride (PVC) tubing (1/16" ID x 3/16" OD, VWR International); the discontinuous organic phase is introduced via a needle (30-gauge) inserted halfway into the tubing. See figure \# for a schematic of the mesofluidic device. Plastic syringes of $50 \mathrm{~mL}$ capacity were filled with the aqueous solution and mounted on a syringe pump (Harvard Apparatus Model 22). For the organic solutions, $1 \mathrm{~mL}$ or $5 \mathrm{~mL}$ syringes were mounted on a second syringe pump (Sage Orion M361). The use of two syringe pumps allowed the flow rates of the solutions to be varied independently. Also, both syringe pumps were calibrated before use via timed pumping of known volumes. Using a luer-to-barb connecter (Upchurch Scientific) the PVC aqueous flow tube was connected to the appropriate syringe. A 30gauge needle (Becton-Dickinson) was attached directly to the organic-solution-containing 
syringe; the needle was then carefully inserted into the wall of the PVC tubing with the tip situated in the middle of the tube channel. When flow was initiated, the effluent and capsules were captured in a crystallizing dish partially filled with deionized water or collected directly into $20 \mathrm{~mL}$ sample vials.

An optical microscope (Leica DM IL) was used to examine the capsules in addition to characterizing the size of the capsules using an ocular scale bar. The polymerized mesocapsules were further characterized by scanning electron microscopy (SEM, LEICA 440) at $10 \mathrm{kV}$ after sputter coating with palladium-gold. Photographs were obtained by a digital camera (Sony DSC-F717) mounted on the optical microscope and by secondary electron imagining with the SEM.

Measurements and Analytical Analysis. The diameters of the capsules were measured within twelve hours of their formation via the ocular scale bar on the optical microscope. One hundred capsules were measured to determine mean capsule size and diameter coefficient of variation. The coefficient of variation $(\mathrm{CV})$ is defined as follows:

$$
\mathrm{CV}=(\sigma / \mu) \cdot 100
$$

where $\sigma$ is the standard deviation of the diameter $[\mu \mathrm{m}]$ and $\mu$ is the number-average diameter of the diameter $[\mu \mathrm{m}]$ to give the coefficient of variation [\%].

Reynolds Number $(R e)$ is defined as follows:

$$
\operatorname{Re}=(d \cdot v \cdot \rho) / \eta
$$

where $d$ is the diameter of the channel $[\mathrm{m}], v$ is the flow rate $[\mathrm{m} / \mathrm{s}], \rho$ is the density of the continuous phase $\left[\mathrm{kg} / \mathrm{m}^{3}\right]$, and $\eta$ is the viscosity of the continuous phase $[\mathrm{Pa} \cdot \mathrm{s}]$. The densities of all solutions were measured by weighing-by-difference of known volumes of solution. Viscosities were measured on a U-tube viscometer. 


\begin{tabular}{|c|c|c|c|}
\hline $\begin{array}{l}\text { Aqueous } \\
\text { Flow Rate } \\
\text { (mL/min) }\end{array}$ & $\begin{array}{c}\text { Sample } \\
\text { Photograph }\end{array}$ & $\begin{array}{c}\text { Average } \\
\text { Diameter } \\
(\mu \mathrm{m})\end{array}$ & $\begin{array}{l}\text { Coefficient of } \\
\text { Variation (\%) }\end{array}$ \\
\hline 2.0 & & 865 & 3.5 \\
\hline 5.0 & & 704 & 4.6 \\
\hline 7.5 & & 554 & 5.7 \\
\hline 11 & & 550 & 4.9 \\
\hline 13 & & 425 & 3.3 \\
\hline 18 & & 365 & 8.6 \\
\hline 25 & & 313 & 8.2 \\
\hline
\end{tabular}

